\title{
Tackling the Backlog
}

By Anna Appleman, Columbia Theological Seminary; Tammy Johnson, Columbia Theological Seminary

ABSTRACT This conversation group provided an opportunity for attendees to share questions and insights to reduce legacy backlogs of print materials.

While libraries are fully engaged in keeping up with the digital environment, many still have legacy backlogs of print materials. Regardless of how backlogs develop, it is usually up to cataloging and technical services staff to deal with them while also acquiring and providing access to new materials. Group leaders shared their experience of reducing an immense legacy backlog of print materials to a manageable amount with limited staff and resources. Topics included assessment, collection development policies, outsourcing, student workers, and strategies for discussing the backlog with administrators.

The conversation began with a brief history of how the backlog developed at the John Bulow Campbell Library, Columbia Theological Seminary. Some contributing factors included the acquisition of other collections, a significant change in student work-study hours, and an automation project that was never completed. While attempts were made over the years to reduce the backlog, what finally worked was a perfect storm comprised of a change in the collection development policy, active weeding, a student worker with aptitude, and funds to pay for a contract worker and outsource certain projects. The discussion continued with identifying what a backlog is, what contributes to its creation, and some of the benefits of tackling the backlog-namely, intellectual and physical control over the collection and a better-quality catalog and collection to support the mission of the institution.

Next, group leaders and participants compiled a list of considerations to be made concerning the backlog:

1. Examine the current collection development policy.

What is the mission of the institution and how does the collection development policy support the curriculum? 
Does processing the backlog fit with the current mission of the library?

Is processing the backlog good stewardship of library resources at this time?

2. Assess the library's current backlog.

Identify the quantity of the legacy backlog

What is the size of the backlog?

How much needs to be addressed at this time?

Identify categories within the backlog

Legacy titles or titles acquired prior to the current

fiscal year

Duplicate copies

DVDs, CDs, other media

Identify tasks associated with addressing the backlog

Cataloging

Physical processing

Weeding

3. Prioritize.

What tasks should be first?

Can the categories be broken down further?

4. Establish criteria for catalog records.

Full records

Partial records

Collection level records

5. Determine cataloging workflow.

How will the workflows be set up?

How does the workflow impact processing of newer materials or other responsibilities and tasks?

6. Identify resources.

Funds-What funds are available? What funds are needed?

Is outsourcing an option?

Staffing-Full time employees, temporary workers, students, volunteers

What other projects and deadlines will be affected?

Cross-training

Plans for celebrations to keep momentum 
7. Facilitate conversation with administrators or directors.

Summarize each of the six areas above and prepare a brief statement that includes:

Size of backlog

History of the backlog

Cost/benefit to the institution

How will it fit with mission of the library and support the institution?

Will additional funding be needed?

Can current funding be reallocated?

A plan for coordination and communication with departments

How will it affect other staff?

Legacy backlogs of print materials exist in libraries for a variety of reasons, and one approach to tackling them will not suit all. Above is a list of considerations to aid cataloging and technical services staff in reducing the backlog to provide a better-quality catalog and collection to support the mission of the institution. This conversation group provided an opportunity for colleagues to share ideas about solving a perennial problem: how to tackle the backlog. 